\title{
Photo-Optical In-Situ Measurement of Drop Size Distributions: Applications in Research and Industry
}

\author{
Robert P. Panckow ${ }^{1,4 *}$, Laura Reinecke ${ }^{2}$, Maria C. Cuellar ${ }^{3}$ and Sebastian Maaß ${ }^{4}$ \\ ${ }^{1}$ Technische Universität Berlin, Fachgebiet Verfahrenstechnik, Ackerstraße 76, 13355 Berlin - Germany \\ ${ }^{2}$ Franken Filtertechnik KG, Max-Planck-Str. 7, 50354 Hürth - Germany \\ ${ }^{3}$ Department of Biotechnology, Delft University of Technology, Van der Maasweg 9, 2629 HZ Delft - The Netherlands \\ ${ }^{4}$ SOPAT GmbH, Boyenstr. 41, 10115 Berlin - Germany \\ e-mail: panckow@tu-berlin.de - laura.reinecke@frankenfilter.com - m.c.cuellar@tudelft.nl - sebastian.maass@sopat.de \\ * Corresponding author
}

\begin{abstract}
The exact knowledge of Drop Size Distributions (DSD) plays a major role in various fields of applications to control and optimise processes as well as reduce waste. In the microbial production of advanced biofuels, oil droplets are produced under turbulent conditions in an aqueous medium containing many surface active components, which might hinder the recovery of the product. Knowledge of DSD is thus essential for process optimisation. This study demonstrates the capability of a photo-optical measurement method for DSD measurement in fermentation broth and in plate separators aimed at cost reduction in the microbial production of advanced biofuels. Measurements were made with model mixtures in a bioreactor, and at the inlet and outlet of a plate separator. In the bioreactor, the method was effective in detecting a broad range of droplet sizes and in differentiating other disperse components (e.g. microbial cells and gas bubbles). In the plate separator, the method was effective in determining the influence of the varied parameters on the separation efficiency.
\end{abstract}

Résumé - Mesure photo-optique in-situ de la distribution des taille des gouttes : applications dans la recherche et l'industrie - La connaissance approfondie de la distribution du diamètre des gouttelettes joue un rôle important dans des diverses applications des contrôles et d'optimisations des processus, de plus elle permet de réduire le gaspillage. Pendant la production microbienne de biocarburants avancés, des gouttelettes d'huiles sont produites sous les effets des turbulences du milieu aqueux contenant beaucoup de substances tensio-actives, ce qui pourrait entraver la récupération du produit. La connaissance de la distribution du diamètre des gouttelettes est donc essentielle pour l'optimisation des processus. Cette étude montre les possibilités offertes par une méthode de mesure photo-optique pour les mesures de la taille des gouttelettes dans des bouillons de fermentations et dans des séparateurs à plaques, ceci vise à réduire les coûts dans la production microbienne de biocarburants avancés. Les mesures ont été effectuées avec des mélanges modèles dans un bioréacteur ainsi qu'à l'entrée et à la sortie d'une plaque de séparation. Dans le bioréacteur, le procédé est efficace dans la détection d'une large gamme de tailles de gouttelettes et dans la différenciation des autres composants dispersés (par exemple des cellules microbiennes et des bulles de gaz). Dans le séparateur à plaque, le procédé est efficace, car il détermine l'influence de différents paramètres sur l'efficacité de la séparation. 


\section{LIST OF SYMBOLS AND/OR NOTATIONS}

$a_{\mathrm{P}} \quad$ Disperse phase surface area per volume $\left(\mu \mathrm{m}^{-1}\right)$

$d_{3,2} \quad$ Sauter mean diameter $(\mu \mathrm{m})$

$d_{\max } \quad$ Maximum diameter $(\mu \mathrm{m})$

$d_{\min } \quad$ Minimum diameter $(\mu \mathrm{m})$

$d_{\mathrm{P}} \quad$ Particle diameter $(\mu \mathrm{m})$

$d_{r X} \quad$ Percentiles of quantity $r(\mu \mathrm{m})$

$k \quad$ Number of bins (-)

$N \quad$ Total number of particles (-)

$Q_{r} \quad$ Cumulative distribution of quantity $r(-)$

$q_{r} \quad$ Density distribution of quantity $r\left(\% \mu \mathrm{m}^{-1}\right)$

$\dot{V} \quad$ Volume flow rate $\left(\mathrm{L} \mathrm{h}^{-1}\right)$

$x \quad$ Size variable $(\mu \mathrm{m})$

\section{GREEK SYMBOLS}

$\Delta \quad$ Difference operator

$\eta_{\mathrm{d}} \quad$ Dynamic viscosity of disperse phase (mPa s)

$\eta_{\mathrm{fl}} \quad$ Dynamic viscosity of fluid (mPa s)

$\rho \quad$ Density $\left(\mathrm{kg} \mathrm{m}^{-3}\right)$

$\sigma_{\mathrm{fl}} \quad$ Interfacial tension between fluids $\left(\mathrm{N} \mathrm{m}^{-1}\right)$

$\varphi_{\mathrm{d}} \quad$ Phase fraction of disperse phase (vol\%)

$\varphi_{\mathrm{fl}} \quad$ Phase fraction of fluid (vol\%)

\section{SUBSCRIPTS}

$0 \quad$ Related to quantity number

3 Related to quantity volume

$i \quad$ Index number

$n \quad$ Related to quantity number

$r \quad$ Type of quantity

$v \quad$ Related to quantity volume

$X \quad$ Percentage

\section{ABBREVIATIONS}

CDF Cumulative Distribution Function

CFD Computational Fluid Dynamics

DSD Drop Size Distribution

FOV Field Of View

GDP Gradient-Direction-Pattern

Img Image

NCC Normalised Cross-Correlation procedure

SMD Sauter Mean Diameter

1-1 Liquid-Liquid

\section{INTRODUCTION}

One of the recent advances in the field of biofuels is the application of synthetic biology to develop microorganisms that produce long chain hydrocarbons, which are also known as advanced biofuels (Cuellar and van der Wielen, 2015). These fuels have been demonstrated in airplanes during the UN Earth Summit in Rio de Janeiro 2012 and public transport buses in São Paulo, Brazil (www.amyris.com).

These fuels are produced by microorganisms converting the substrate (glucose, glycerol) to the biofuel product, which is secreted into the fermentation broth, resulting in a dispersion of product droplets in an aqueous phase from which the product then has to be recovered. The turbulent conditions in the bioreactor and the presence of surface active components originating from the feedstock or the microbial process lead to product stabilisation in the form of emulsions (Heeres et al., 2014, 2015). As a consequence, product recovery strategies often involve intensive centrifugation, shifts in $\mathrm{pH}$ and temperature, and/or the use of deemulsifiers. However, for economically feasible production of the biofuel, the recovery process has to be cheap, so a low cost process technology should be used. Technologies such as gas enhanced oil recovery (Heeres et al., 2016), magnetic nanoparticles (Furtado et al., 2015) and catastrophic phase inversion (Glonke et al., 2016) have been proposed as alternative de-emulsification methods. Furthermore, gravity separators such as plate droplet separators offer opportunities for either concentrating the disperse phase prior to one of the de-emulsification methods above, or for the complete separation of the disperse phase when the droplet stabilisation can be mitigated during the conversion process. The latter is, however, still an object of research. The actual Drop Size Distribution (DSD) obtained after the microbial conversion process, on the other hand, is influenced by broth composition, reactor parameters, oil fraction, type of microorganism and fermentation age, among others. For this type of system off-line measurement methods are often not suitable due to non-homogeneous sampling, changes in DSD during sample procedure and ageing of the sample. In-situ measurement methods overcome these issues, but should be able to differentiate other disperse phases present in the broth such as gas bubbles and the microorganisms, and must not compromise the sterility of the system.

The separation of Liquid-Liquid (1-l) dispersions by means of gravity separators is a standard operation in process engineering. They are typically used when immiscible two-phase mixtures from organic and aqueous phases have to be separated. This is the case in a variety of upstream and downstream processes in chemical industry, petroleum industry or pharmaceutical industry. Internal components such as plates have a significant impact on the phase 
separation (Mungma et al., 2014). The dimensioning of gravity or plate droplet separators is currently often an empirical issue. The design is based on information about settling behaviour and residence time and also coalescence characteristics (Schlieper et al., 2004). This can result in overdimensioning of these apparatuses to guarantee sufficient separation efficiency. Besides relevant variables such as viscosity of the involved fluids $\eta_{\mathrm{ff}}$, interfacial tension $\sigma_{\mathrm{fl}}$ between these fluids or phase fraction $\varphi_{\mathrm{fl}}$, the DSD $q_{0}$ based on the particle number and the DSD $q_{3}$ based on the particle volume, play a crucial role in the selection of design parameters. The inline measurement of the DSD at the inlet and outlet of a gravity or plate droplet separator is a possible option to study the influence of the parameters mentioned above on the separation. Based on these measurements an improved design method for gravity separators using multiphase flow Computational Fluid Dynamics (CFD) should be established in the future.

In this contribution, we investigated the applicability of in-situ droplet size measurement by a photo-optical method both in a fermentation broth and in plate droplet separators, aimed at the development of efficient and low cost separation methods for the production of advanced biofuels.

\section{IN-SITU DROPLET SIZE MEASUREMENT BY PHOTO-OPTICAL ENDOSCOPE TECHNIQUE}

\subsection{Drop Size Measurements}

The aim of this study is to evaluate the applicability of an in-situ measurement technique for particle sizes as a tool in developing new process and reactor concepts containing $1-1$ dispersions. Knowledge of the DSD is essential for the development, evaluation and implementation (e.g. in CFD code) of model approaches which will help to overcome the gap between industrial process practice and detailed process understanding. Therefore, various experiments have been carried out, analysing the drop size as a function of reactor design parameters, operating conditions and physical characteristics of the $1-1$ dispersion.

A broad overview of existing measurement techniques can be found in (Abidin et al., 2013). They describe the different methods of measurement which can be classified into in-situ and external measurement. Two main groups of measurement techniques are reviewed by Abidin et al. (2013). Several issues regarding the applications of the techniques and possible ways to overcome the problems are discussed. They conclude that laser-based systems provide fast in-situ measurements which are useful for online monitoring and detecting process changes but are unable to deliver reliable drop size and distribution values. In-situ image analysis techniques give accurate measurement of drop size and, with development of automated image analysis, they can be used for real-time monitoring and process control.

In light of the studies and literature reports already mentioned, the measurement of the DSD in highly concentrated emulsions was carried out with the reliable endoscope technique in combination with image analysis (Ritter and Kraume, 2000), see Figure 1 for different example images - for more details see (www.sopat.eu). They suggested a minimum number of 200 particles to form one sample for one DSD as a reliable number for statistical demands (Ritter and Kraume, 1999). This number was always exceeded by a minimum factor of $c a .4$ for all investigated cases.

Figure 1 shows clearly the broad applicability of the endoscope measurement technique for different particulate systems. Different endoscopes with different lenses which create different magnifications were used to take these different example images. The lens with the highest magnification was used for the $n$-butyl chloride/water system. The smallest measurable drop diameter with this lens is around $10 \mu \mathrm{m}$. The largest screen size was achieved with the lens which was used for the presented air/water system (Fig. 1). The diameter of the image was $8000 \mu \mathrm{m}$.

Particularly in fast coalescing systems, the quantitative size measurement of fluid disperse phases is a major challenge. In contrast to sampling, which is time-consuming and involves the danger of adulteration, an in-situ working analysis method with high spatial and temporal resolution is selected to measure the DSD (Schlüter, 2011; Panckow et al., 2015).

\subsection{Demands on In-Situ Devices}

The photo-optical SOPAT measuring technique for particle sizing is capable of acquiring raw data (two-dimensional images) of the disperse phase (in this study: droplets) during the process and measure the sizes by means of automated image analysis, see Figure 2. The software analysis processing the various raw data obtainable utilizing the broad variety of chemical apparatus is described in detail in Section 1.3.

For precise image analysis, high quality images are necessary. Therefore the selected system consists of HD lenses, either endoscopic or microscopic ones. The optical lenses are surrounded by a protection tube (material: stainless steel 1.4571 or Hastelloy ${ }^{\circledR}$ C-22) and they represent the front part of the probe. The attached housing protects a 6 megapixels camera from water and dust fulfilling IP65 requirements.

As is known from microscopy, different magnifications for analysing different particle size ranges can be achieved by switching the described probe manually. The highest magnification allows particle measurements starting at $900 \mathrm{~nm}$ in terms of minimum measured diameter. By changing the 

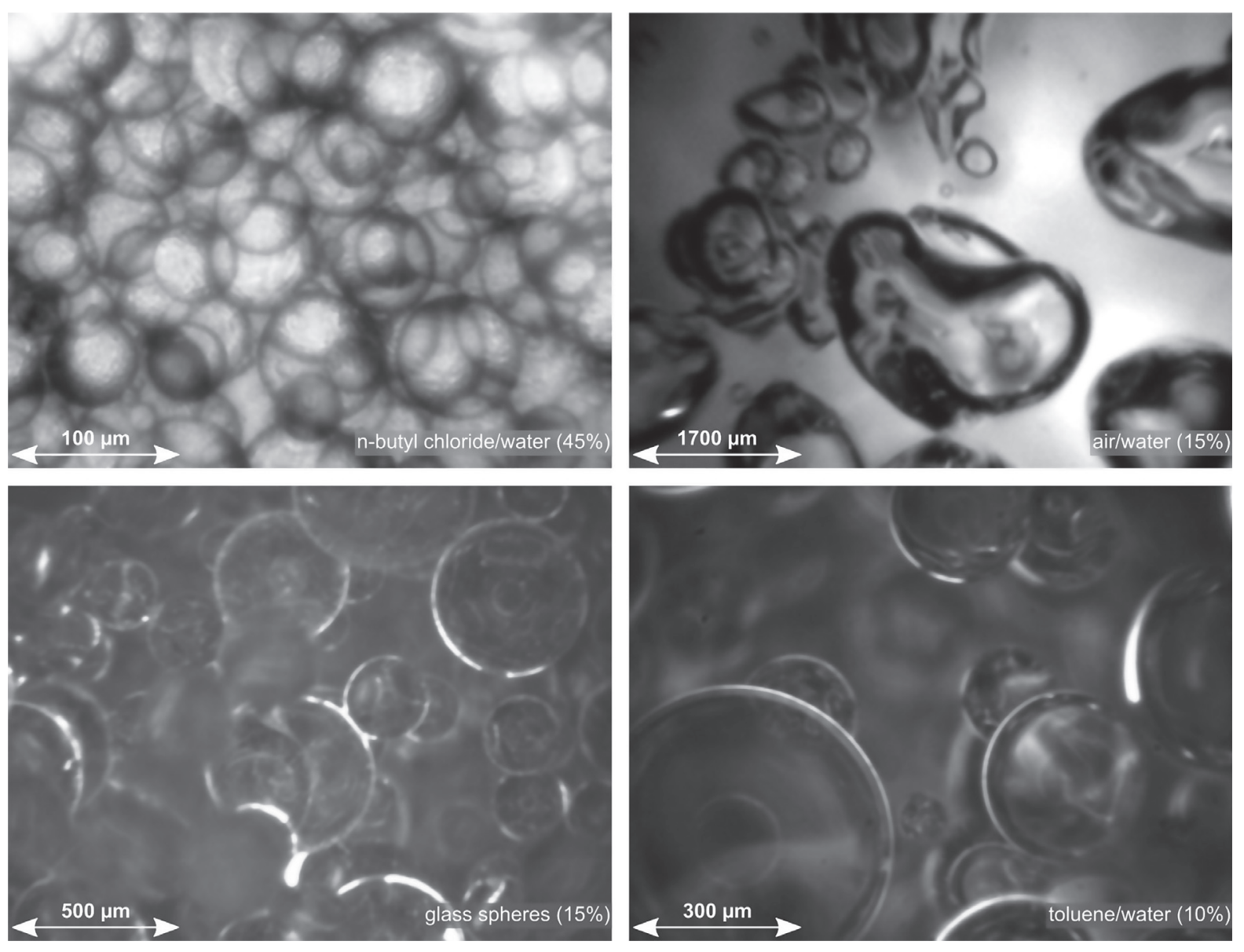

\section{Figure 1}

Example image gallery: representative samples taken with the endoscope technique using different lenses according to the expected particle size for different systems.

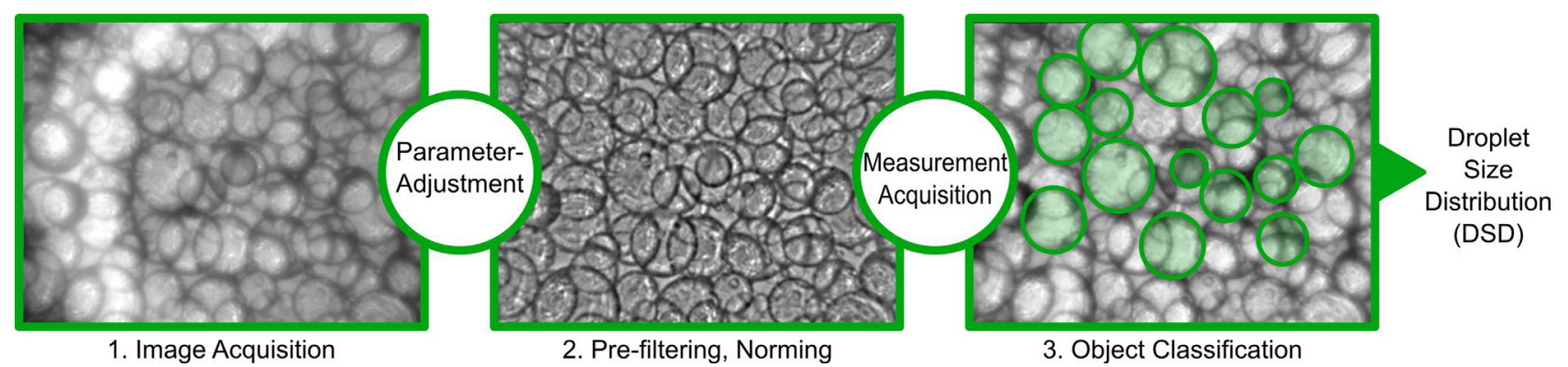

Figure 2

Photo-optical measuring method for particle size distributions.

probe, a larger Field Of View (FOV) can be achieved. The largest available FOV from the discussed in-situ probes is $24 \mathrm{~mm}$. This allows particle analyses up to $9 \mathrm{~mm}$ in particle diameter.
The camera is controlling a xenon flash. The latter ensures high illumination intensities in a very short time. The flash time varies, depending on the intensity, from $2 \mu \mathrm{s}$ for the lowest intensity up to $8 \mu$ s for the highest intensity. 

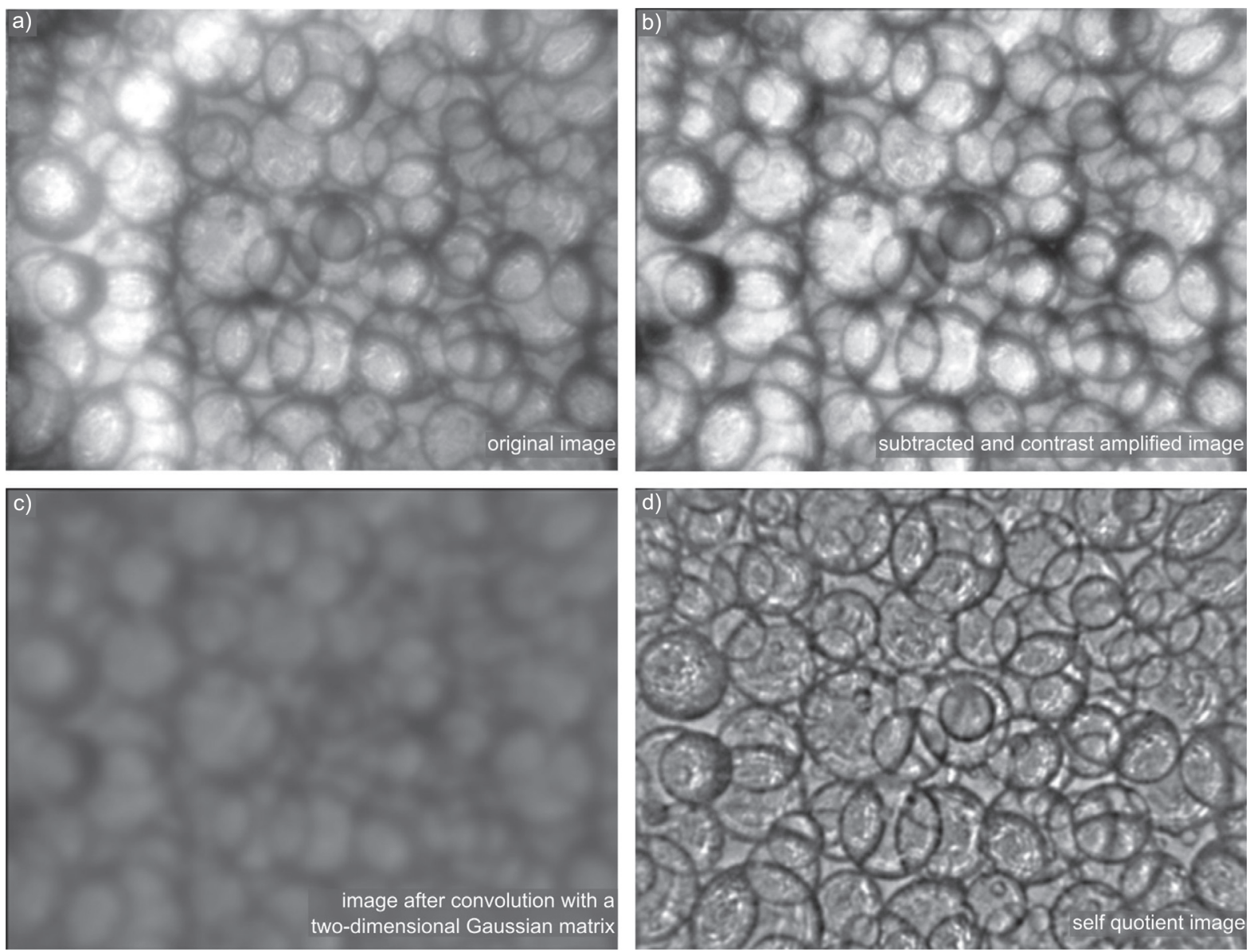

Figure 3

Image processing steps to remove redundant information and increase the ability to detect possible drop circles, (Maaß et al., 2012).

This ensures sharp image capture even from fast moving particles. The flash is inside the central box (Fig. 10, right in Sect. 3.1). The light from the stroboscope is transported by a fibre-optic. This ensures highly homogeneous illumination across the FOV. The fibre-optic is flexible but is surrounded by a robust and IP65 certified protective hose. Using a diverse variety of flanges, the system can easily be installed in pre-existing apparatuses. The probes tolerate a process pressure up to 150 bar, however for special applications even higher pressure can be achieved. The image analysis is carried out on a work station with four Intel $^{\circledR}$ Core $^{\mathrm{TM}}$ i7 processors. The details of the image analysis software are given in Section 1.3.

\subsection{Image Analysis Working Principle}

Various commercial software packages are now available that analyse images automatically and measure the size of the droplets. The qualities of the results from these packages differ and depend on a number of variables, including the quality of the initial images. Custom software can be written to incorporate previously validated image processing algorithms. There is also software available allowing a manual marking of droplets on images which are then measured by the computer. This process is extremely time consuming, but generally considered essential for producing accurate results as well as checking the performance of automatic software (Brown et al., 2004).

To overcome the drawback of time consuming manual quantification using photo-optical methods with image analysis, a fully automated method based on MATLAB ${ }^{\circledR}$ was implemented and put into practice. The software employs a Normalised Cross-Correlation (NCC) procedure algorithm, which is explained in detail along with the prefiltering which was employed by (Maßß et al., 2012). Additionally, it avoids human generated bias by different observers, also shown in (Maaß et al., 2012).

In order to ensure robust and accurate drop detection, a series of images is first pre-filtered to remove irrelevant and misleading image information. This is done with image subtraction using the integrated sequence as difference image (compare Fig. $3 \mathrm{a}$ and $3 \mathrm{~b}$ ). The noise in the pictures 
is reduced by the self-quotient image method (Gopalan and Jacobs, 2010). This operation norms the intensity of every local pixel based on the local environment. It is carried out by division of the processed image (Fig. 3b) by a smoothed version of itself, see Figure $3 \mathrm{c}$ after convolution with a Gaussian matrix.

Figure $3 \mathrm{~d}$ shows the self-quotient image which emphasises the changes of the intensities from the original image. This results in an independence from any illumination or process variation.

Then the drop recognition follows. It consists of three steps: pattern recognition by correlation of pre-filtered gradients with search samples, the pre-selection of plausible circle coordinates, and the classification of each of those circles by an exact edge examination. The software employs a NCC algorithm (Lewis, 1995) to evaluate possible drop matches, see Maaß et al. (2012) for more technical details and results.

The approaches described here are comparable to the work of Rojas-Domínguez et al. (2015). They propose a transformation of the denominated Gradient-DirectionPattern (GDP). The GDP is the described pattern matching algorithm which is currently only implemented to find circular patterns. Therefore the existing image analysis technology by SOPAT was further developed to take also irregular shaped particles into account (Panckow et al., 2015).

\section{APPLICATION: FERMENTATION BROTH}

\subsection{Chemical Systems and Operating Conditions}

The model fermentation broth was obtained by fed-batch cultivation under similar conditions to those reported in Cuellar et al. (2009). The fermentation broth contained $c a$. $50 \mathrm{~g} \mathrm{~L}^{-1}$ of $E$. coli $\mathrm{K} 12$ cells on a dry weight basis, to which ca. 10 vol\% hexadecane had been added. For the measurement purposes of this paper a volume of 1-2 L of this mixture was transferred to a $7 \mathrm{~L}$ Applikon bioreactor operating at a stirrer speed of $300 \mathrm{rpm}$. When indicated, air was sparged at a flow rate of $\dot{V}=1.5 \mathrm{~L} \mathrm{~min}^{-1}$.

\subsection{Specifications of the Installed Photo-Optical Probe}

The probe "SOPAT $M M$ " used in the fermentation broth system contains a high magnification microscopic lens system projecting an image from the inside of the bioreactor with a cross section diameter (the FOV) of $385 \mu \mathrm{m}$. It is transported onto the camera sensor, being $15.989 \mathrm{~mm}$ in diagonal, with a resolution of $2752 \times 2200$ pixels, creating a circular projection of the observed measurement volume, see Figure 6. To convert the discretised objects in pixels, acquired at the camera sensor, back to the unit of the real

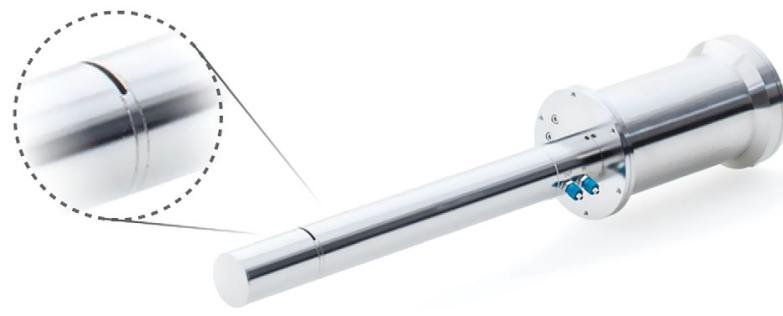

Figure 4

Probe "SOPAT $M M$ " with adjustable flow gap used for in-situ droplet size measurement in the fermentation broth.

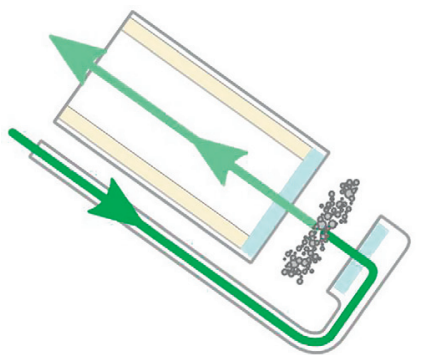

a)

Figure 5

Probe specification: a) illumination of the particles by transmission of collimated light, b) reducible resolution of the camera sensor by binning.

particles, a conversion factor of $0.175 \mu \mathrm{m} / \mathrm{pixel}$ has to be used. The probe is able to detect particles in the range of ca. $1 \mu \mathrm{m}$ to $170 \mu \mathrm{m}$. It has a wetted diameter of $24.5 \mathrm{~mm}$ and a maximum wetted length of $320 \mathrm{~mm}$ with a flow gap located on its tip, see Figure 4.

This flow gap has an adjustable size with a maximum of $2 \mathrm{~mm}$ ranging down to $200 \mu \mathrm{m}$. The measured volume is illuminated from the opposite side at the very end of the tip of the probe by collimated light, see Figure 5a.

This illumination method by an opposing back light leads to a projection of the photographed particles onto the sensor as dark objects with strong contrast in front of a bright background. The control software of the probe allows binning for the camera sensor to be enabled, see the schematic drawing in Figure 5b. By doing this, the values of a specified number of pixels are added and their number is set to one single pixel. This results in a brighter image with a lower resolution. For example in Figure 5b, the binning $2 \times 2$ results in a combination of 2 vertical and 2 horizontal pixels to one single pixel that is four times as bright as (the average of) the 4 native pixels and the segment thereby is reduced in resolution by the same factor of 4 . 
TABLE 1

Experiments in the model fermentation broth system.

\begin{tabular}{c|c|c|c|c|c|c|c}
\hline ID & Time (min) & Gap (mm) & Binning & Gain & Aeration & Images $^{\text {Detections Img }}{ }^{-1}$ \\
\hline $\mathrm{e} 01$ & 0 & 2 & $2 \times 2$ & 14 & Non-aerated & 250 & 3.2 \\
\hline $\mathrm{e} 02$ & 18 & 1 & $2 \times 2$ & 14 & Non-aerated & 250 & 7.9 \\
\hline $\mathrm{e} 03$ & 22 & 1 & $2 \times 2$ & 14 & Aerated & 250 & 8.3 \\
\hline $\mathrm{e} 04$ & 32 & 0.5 & $2 \times 2$ & $3-5$ & Non-aerated & $4 \times 250$ & 13.3 \\
\hline $\mathrm{e} 05$ & 60 & 1 & $2 \times 2$ & 12 & Non-aerated & $3 \times 250$ & 13.6 \\
\hline $\mathrm{e} 06$ & 87 & 0.2 & $1 \times 1$ & $0-9$ & Non-aerated & $5 \times 250$ & 23.9 \\
\hline
\end{tabular}

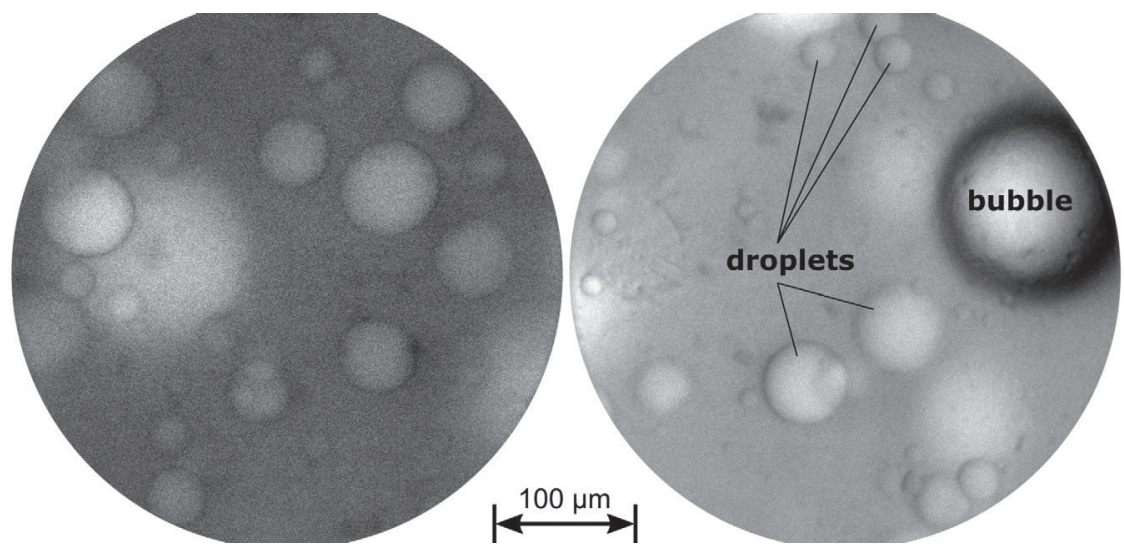

a)

Figure 6

Comparison of different gap sizes: a) e01 with $2 \mathrm{~mm}$, b) e03 with $1 \mathrm{~mm}$, c) e 06 with $200 \mu \mathrm{m}$; all experiments have microbial cells and oil droplets as disperse phases, b) e 03 additionally had air bubbles.

\subsection{Analytical Methodology}

The experiments performed and their corresponding start time (relative to the start of experiment e01) are shown in Table 1. Variations were made on the gap and whether the mixture was aerated or not.

For experiment $\mathrm{e} 06$ a reduced binning was used in order to measure with a higher resolution than in the other experiments. The resulting images, which are four times darker than those with binning $2 \times 2$, were still bright enough to be usable, since a very thin gap of $200 \mu \mathrm{m}$ was applied. By setting a gain, a further adjustment of the brightness of the resulting output image is possible: by increasing the gain, i.e. amplifying the signal of the impinging photons on the camera sensor, the background noise is increased as well. However, in order to get a sufficient brightness of the resulting pictures, for the larger gap sizes in e01-e03, e 05 a higher gain was applied. In the last two columns of Table 1 the absolute numbers of images, having been acquired and used for the analysis of each experiment, as well as the counts of particles per single image (Detections $\mathrm{Img}^{-1}$ ) are reported. The influence of the gap size as well as the presence of another disperse phase besides the disperse phase of interest (here: droplets) is presented in Figure 6.

The images shown here represent a contrast expanded version of the acquired raw data, stretching the brightest grey value to white and the darkest grey value to black. Hereby, the images become visible for the human eye which is not able to distinguish between small differences in grey values. Especially the image in Figure 6a would appear as pure grey without contrast expansion. These distorted images are only intended for a clearer visualisation and are not used by the software, which is fed with the original images as raw data.

In the images acquired with the big gap of $2 \mathrm{~mm}$ in experiment $\mathrm{e} 01$, there is a low contrast resulting from the refraction of light in the thick layer of fermentation broth 


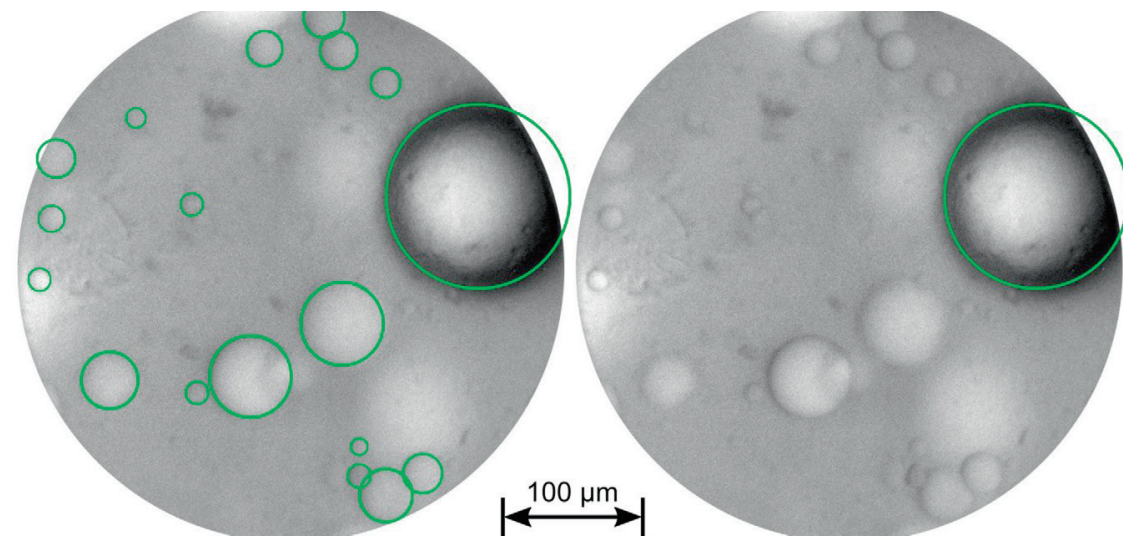

a)

b)

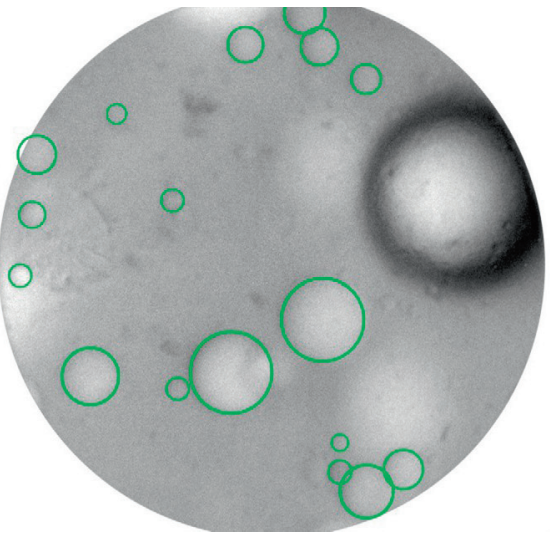

c)

Figure 7

Working principle to distinguish between different disperse phases, particle detections marked as green circles: a) detection of all objects corresponding to the taught pattern, b) only detecting the high contrast bubbles c) subtraction of the detections a) and b) to get the size distribution of only the droplets.

leading to a high overall diffuseness, see Figure 6a. Therefore, after the contrast expansion of the narrow-ranged grey values, these images appear very noisy. The appearance of small droplets is strongly weakened and the number of droplets detected is low, which is why the setup in experiment $\mathrm{e} 01$ is not suitable to detect a reliable DSD of the disperse oil, although the absolute number of detections $(N=788)$ fulfils the criterion of a minimum number of 200 particles (Ritter and Kraume, 1999), see Section 1.1. With a smaller gap size, see Figures $6 \mathrm{~b}$ and $6 \mathrm{c}$, the contrast increases and smaller droplets become visible. For the smallest gap of $200 \mu \mathrm{m}$, the structures of the cell agglomerates and other components (e.g. dirt particles) become visible in the emulsion. They emerge as background structures in the dense (as compared to the other disperse phases) cell emulsion, see Figure 6c.

These background structures as well as the bubbles in e03, see Figure 6b, are not analysed in this study. Therefore the software was parametrised to find the droplets by creating a pattern containing information describing the appearance (grey values) of droplets in the SOPAT software, see Section 1.3 for details about the software algorithms for particle recognition. Combined or separated size distributions of different particle types can be produced by parametrising the software to detect additionally/only the specific particle type (i.e. droplets, bubbles and/or cell agglomerates), see Figure 7.

This mechanism for the detection of different disperse phases is illustrated by the subtraction of two size distributions: Figure 7a "droplets + bubbles"-distribution and Figure $7 \mathrm{~b}$ "bubbles only"-distribution. Each of the green circles in the figure marks a particle detected by the automated software with its corresponding location and size on the photograph. In the first step, the software is parametrised to detect the droplet size distribution using a pattern representing the droplet appearance (grey values). Since the bubbles cause a strong refraction of the light and result in a high contrast projection on the camera sensor - resulting in a high quality pattern match - they are likely to be detected by this first droplet pattern as well, see Figure 7a. The resulting particle size distribution contains both the liquid droplets and the gaseous bubble phase. By creating a second pattern that represents the bubbles only a second distribution can be obtained, see Figure 7b, containing no droplets at all since their match quality (in comparison to the bubble pattern) is too low. The subtraction of these two particle detections, "droplets + bubbles"-distribution and "bubbles only"-distribution, results in the desired "droplets only"-distribution, see Figure 7c. These two patterns for droplets and bubbles do not lead to erroneous detections by misinterpretation of the small cell structures in the background, but only classify the droplet and bubble phase, which are clearly distinguishable from the cells. This procedure of distinguishing between different disperse phases is possible as long as their optical appearance (grey values, object borders, sizes) are sufficiently different. A basic prerequisite is the possibility of a clear identification and distinction with the human eye in order to achieve a consistent training of the software and thus a reliable size analysis. The detection of the cell size distribution is not part of this study. In order to measure it in the investigated fermentation broth, very small gaps (Fig. 6c $200 \mu \mathrm{m}$ or smaller) have to be applied to achieve an appropriate visualisation - and thus identification by the human eye of the single cell structures.

However, besides the advantages mentioned above when choosing a small gap, the exclusion of big droplets and an 
TABLE 2

Characteristic values measured in the model fermentation broth system.

\begin{tabular}{c|c|c|c|c|c|c}
\hline $\mathrm{ID}$ & $d_{3,2}(\mu \mathrm{m})$ & $d_{n 1}(\mu \mathrm{m})$ & $d_{n 95}(\mu \mathrm{m})$ & $d_{\mathrm{v} 1}(\mu \mathrm{m})$ & $d_{\mathrm{v} 90}(\mu \mathrm{m})$ & $d_{\max }(\mu \mathrm{m})$ \\
\hline $\mathrm{e} 01$ & 64.87 & 21.42 & 81.20 & 29.40 & 109.39 & 221.20 \\
\hline $\mathrm{e} 02$ & 86.82 & 18.43 & 107.95 & 27.53 & 151.96 \\
\hline $\mathrm{e} 03$ & 77.23 & 18.38 & 98.59 & 26.13 & 234.96 \\
\hline $\mathrm{e} 04$ & 96.63 & 17.50 & 111.77 & 28.93 & 241.27 & 368.67 \\
\hline $\mathrm{e} 05$ & 106.10 & 18.43 & 120.17 & 33.60 & 243.13 & 325.73 \\
\hline $\mathrm{e} 06$ & 82.54 & 9.55 & 81.32 & 20.10 & 208.42 & 269.73 \\
\hline
\end{tabular}

inhibited flow through the gap could occur, especially for higher viscosities of the analysed emulsion.

For further discussion of the measured drop sizes in Section 2.4 as well as Sections 3.2 and 3.3 the following formulas have been adapted. As the main representations of the DSD, the density distributions of number $q_{0}$ and of volume $q_{3}$ as well as the cumulative distributions of number $Q_{0}$ and of volume $Q_{3}$ are used in this paper. The first represent the likelihood of the occurrence of a specific event $x$ (here: particle diameter $d_{\mathrm{P}}$ ) based on the type of quantity $r$ (i.e. $r=0$ for number, $r=3$ for volume). Their general mathematical relationship is stated in Equation (1).

$$
Q_{r}\left(x_{i}\right)=\int_{x_{\min }}^{x_{i}} q_{r}(x) d x
$$

In particle characterisation the specific event $x$ indicates a certain particle feature and could also represent, for example, circularity, colour, inner structure, membrane thickness and many others. In this paper, only the distributions of the feature "particle diameter $d_{\mathrm{P}}$ " are addressed. As a commonly used characteristic value in particle sizing, the Sauter Mean Diameter (SMD), see Equation (2), relates the available source/sink (volume) to the means of transportation (area) and therefore provides an essential parameter when characterising heat and mass transfer in chemical processes.

$$
d_{3,2}=\frac{6}{a_{\mathrm{P}}}=\sum_{i=1}^{N} d_{\mathrm{P}, i}^{3} / \sum_{i=1}^{N} d_{\mathrm{P}, i}^{2}
$$

Herein $a_{\mathrm{P}}$ is the characteristic surface area per unit volume of the disperse phase and $N$ is the total number of particles. Using Equation (2) to calculate the SMD, spherical particles are assumed. Besides averaged diameters like the SMD, percentiles $d_{r X}$ are used to characterise distributions. They indicate that the cumulative distribution exceeds a certain percentage $X$ of the total quantity $r$ at the given diameter $d$. For example, a characteristic diameter $d_{n 10}=15 \mu \mathrm{m}$ indicates that $10 \%$ of all particle diameters are less than $15 \mu \mathrm{m}$ and $90 \%$ are greater than or equal to $15 \mu \mathrm{m}$. Instead of numbers, the type of quantity $r$ is usually expressed in letters $(n-$ number, $v$ - volume) when using percentiles. Often $d_{n 1}, d_{n 99}$ or $d_{n 5}, d_{n 95}$ or $d_{v 1}, d_{v 99}$ are used instead of the absolute minimum and maximum diameter of the distribution due to statistical outliers. When transformations from the dimension length to volume (or vice versa) are made, the droplets are always assumed to be spherical.

\subsection{Results and Discussion}

Since this study is focused on the size distribution of droplets and there are only 15 bubbles present on the 250 images of e03 (Tab. 1), it is not intended to present and discuss the "bubbles only"-distribution, see Figure 7 in Section 2.3. The measured average sizes represented as $\operatorname{SMD} d_{3,2}$ as well as selected percentiles are shown in Table 2 .

In all of the experiments (except e06) a binning of $2 \times 2$ was used, see Table 1 . In spite of the significant opacity of the system under consideration, by using a binning it was still possible to visualise the disperse phases, even for the large gap size. Without the effect of binning, the images for experiments $\mathrm{e} 01, \mathrm{e} 02, \mathrm{e} 03$ and $\mathrm{e} 05$ (gap $\geq 1 \mathrm{~mm}$ ) would have been too dark to analyse. The brighter and richer in contrast the objects appear on the camera sensor, the more reliably the automatic image analysis algorithms can operate: the probability of pre-selection of a plausible circle coordinate and classification by exact edge examination (Sect. 1.3) increases, and the probability of false detections decreases. As mentioned in Section 2.3, the setup of experiment $\mathrm{e} 01$ has been deemed unsuitable for the system under consideration. As can be seen by the values in Table 2, e01 results in the narrowest distribution, having the maximum values for $d_{n 1}, d_{v 1}$ and the minimum values for $d_{n 95}, d_{v 90}$, $d_{\max }$. The calculated values in Table 2 show that the very small droplets could not be detected because of the high diffuseness. This is due to the influence of the gap on the 

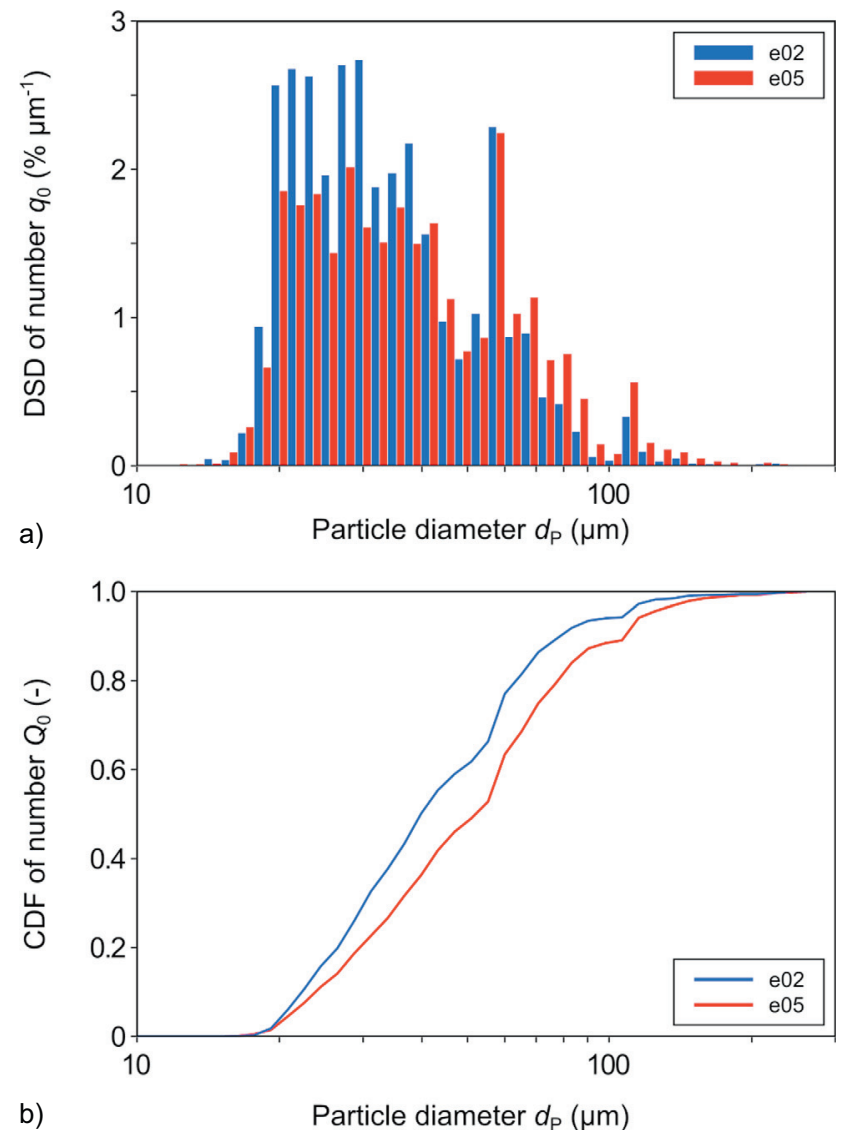

b)

Figure 8

Comparison of oil DSD in fermentation broth at different times: $\mathrm{e} 02$ (18 $\mathrm{min}$ ) and $\mathrm{e} 05(60 \mathrm{~min})$ as a) density distribution $q_{0}$ and b) cumulative distribution $Q_{0}$.

detection: a large gap will result in better (more realistic, unhindered) flow conditions at the measurement point, but will produce more diffuse images, whereas a small gap will result in clearer images that are richer in contrast, but large droplets could be excluded by the constrained flow through the gap. The gap influence is illustrated in Figure 6.

In Table 2 the two values $d_{v 90}$ and $d_{\max }$, both representing the upper diameters of the DSD, are compared. The clearest indication that $d_{\max }$ is strongly influenced by outliers can be seen in experiment e04. Only 18 particles have a diameter above $d_{v 90}=241.27 \mu \mathrm{m}$, one of them with $d_{\mathrm{P}}=$ $d_{\max }=368.67 \mu \mathrm{m}$. This influence arises from the fact that a few large droplets have a significant effect on the volume-based distribution, in this case 18 droplets cover $10 \%$ of the volume of all detected droplets. The relevance of these few large droplets becomes even more obvious when considering the number distribution: for the same experiment (e04) with $d_{n 95}=111.77 \mu \mathrm{m}$, the vast majority of droplets lie below this value. This means only $5 \%$ ( $\approx 667$ particles $)$ of
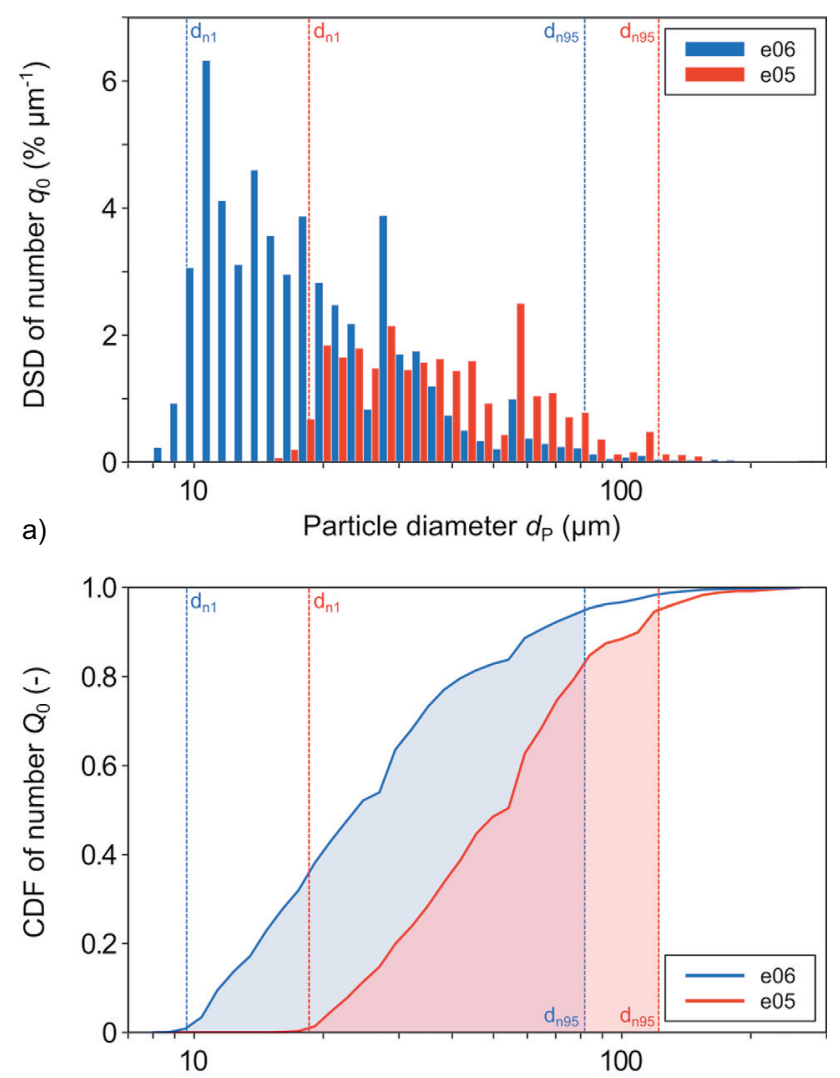

b)

Particle diameter $d_{p}(\mu m)$

Figure 9

Ability to detect droplets below $20 \mu \mathrm{m}$ by applying a thinner gap: e06 (200 $\mu \mathrm{m}$ gap) compared to e05 (1 mm gap), plotted as a) density distribution $q_{0}$ of number and b) cumulative distribution $Q_{0}$ of number.

the droplets detected are bigger than $111.77 \mu \mathrm{m}$, with one of these having the maximum diameter $d_{\max } \gg d_{n 95}$. In Section 3.3, a direct comparison of $Q_{0}$ and $Q_{3}$ shed light on the relationship between the number- and volume-based distributions.

These values indicate a longer right tail of the droplet size distribution, see also Figures $8 \mathrm{a}$ and $9 \mathrm{a}$. The small number of the total particles $N=13,345$ detected in e04 which strongly influence the maximum diameter demonstrates the relevance of statistical interpretation considering outliers, and should warn of misinterpretation of these values located at the very end of the DSD. The appearance of these very large droplets above the reliable detection limit of the probe type $M M$ (170 $\mu \mathrm{m}$, Sect. 2.2) could indicate a very broad distribution and the presence of a higher number of big droplets which are cut off in the measured distribution. This assumption has to be investigated in future studies by using a probe for which the measurement range ends significantly above $400 \mu \mathrm{m}$. 


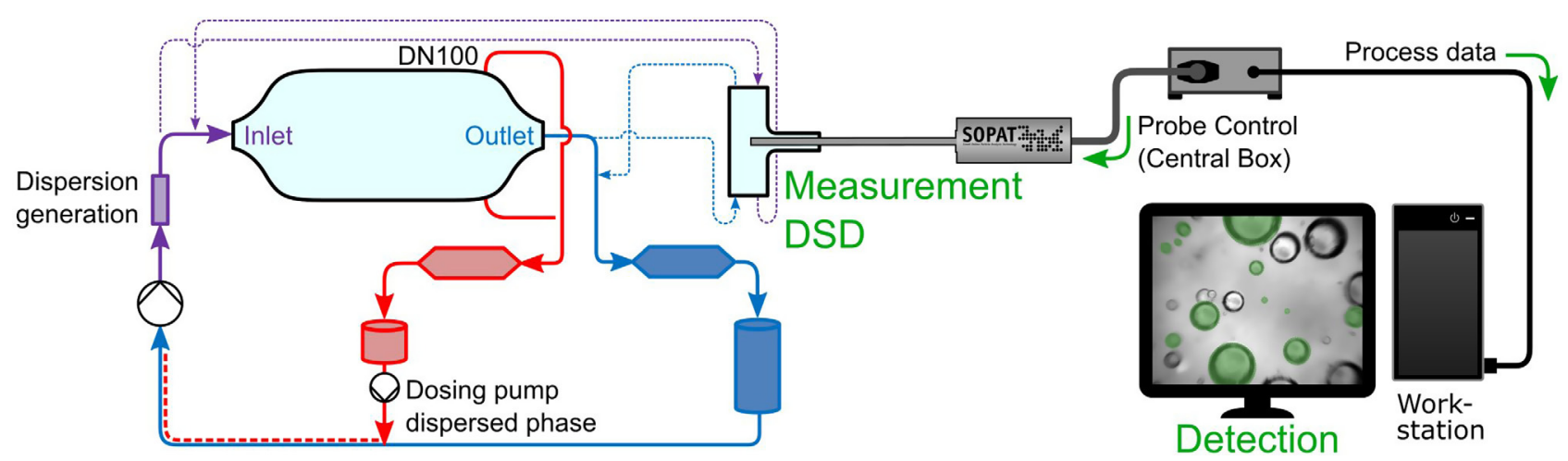

Figure 10

Experimental setup for investigating the plate droplet separator.

The influence of aeration on the drop sizes can be seen from the calculated diameters in Table 2. Comparing e02 with e03 after having increased the air flow from $\dot{V}=0 \mathrm{~L} \mathrm{~min}^{-1}$ to $\dot{V}=1.5 \mathrm{~L} \mathrm{~min}^{-1}$, all the characteristic values are lower, resulting in a slight shift to smaller diameters. Furthermore an increased SMD can be observed over time by comparing experiments e 02 and e 05 , see Table 2 . The repetition of experiment $\mathrm{e} 02$ as $\mathrm{e} 05$ with the same probe configuration showed reasonable results considering the range of drop sizes in the distribution, see Figure 8.

It should be kept in mind that the system was deliberately disturbed by aeration (e03) in between experiments $\mathrm{e} 02$ and e05. A significantly higher number of droplets were detected at the later time in e05, see Table 1 . The shift to bigger droplets, resulting in a higher SMD, may be the result of advanced biological conversion over time in combination with the forced increase of transport processes by aeration in $\mathrm{e} 03$.

In Figures 8 and 9, the number of bins $k$ is chosen to be 40. Following Sturges' Rule $k=\left(1+\log _{2} N\right)$, the calculated number of bins should be chosen such that $k=16$ for the maximum occurring particle count, viz. $N=29,861$ in e06 (Sturges, 1926). Since Sturges' Rule is known to lead to an over-smoothed histogram, especially for large samples, and only considers normal, not skewed distributions (Legg et al., 2013), a higher number was chosen. This also results in a more representative Cumulative Distribution Function (CDF) and leads to preservation of the shape of both density distributions in Figure 9 although they span different intervals. The width of the bins grows accordingly with base 10 resulting in equally broad appearing bars over a logarithmic scale.

The capacity of the system to detect very small droplets by applying a thin gap can be seen when comparing e 05 and e06, see Figure 9. In this figure, the percentiles $d_{n 1}$ and $d_{n 95}$ from Table 2 are also plotted. By comparing the percentiles $d_{n 1}$ of both experiments, the lowered minimum of the detection range for the thin gap $(200 \mu \mathrm{m}$, e 06) can clearly be seen. On the other hand, the big droplets seem distorted when applying a thin gap; compare percentiles $d_{n 95}$, Figure 9 as well as $d_{v 90}$ and $d_{\max }$ in Table 2.

The probe was able to measure the oil droplets in a broad size range and, with the usage of a very thin gap, even observe microbial cell structures (see experiment e06 in Fig. $6 \mathrm{c}$ and Tab. 1) and to differentiate among gas bubbles, see Figures $6 \mathrm{~b}$ and 7.

\section{APPLICATION: PLATE DROPLET SEPARATORS}

\subsection{Chemical Systems and Operating Conditions}

For the investigation of the parameters mentioned in the introduction (e.g. $\left.\eta_{\mathrm{fl}}, \varphi_{\mathrm{fl}}\right)$ which influence the phase separation in gravity or plate droplet separators, a laboratory plant DN100 was built, see Figure 10. It is operated in circulation.

The main part of the laboratory plant is a separator of $100 \mathrm{~mm}$ diameter and a length of $400 \mathrm{~mm}$. It operates both with and without plate internals. Frequency converters are used to control the pump flow rate of the main and dispersed phases to ensure a constant volume flow as well as a certain phase fraction of the dispersed phase. Furthermore, the plant consists of two more fibre bed phase separators to prevent enrichment of non-separated droplets in each phase. The DSD at the inlet of the phase separator is produced mechanically by a special dispersing unit and can be reproducibly adjusted in the range 1 to 1000 microns. After a steady state is reached in the separator (usually after $20 \mathrm{~min}$ ) the in-situ measurement of the DSD at the inlet and outlet is recorded. For these experiments, a photooptical probe ("SOPAT $S c$ ") with a measuring range of 12 to 1500 microns is used with an attached reflection adapter generating a flow gap of $5 \mathrm{~mm}$. A description of how to obtain an adequate adjustment of the latter is given in 
TABLE 3

Specifications of the oils used as disperse phases.

\begin{tabular}{c|c|c|c|c}
\hline & $\rho\left(\mathrm{kg} \mathrm{m}^{-3}\right)$ at $25^{\circ} \mathrm{C}$ & $\eta_{\mathrm{d}}(\mathrm{mPa} \mathrm{s})$ at $20{ }^{\circ} \mathrm{C}$ & Type & Supplier \\
\hline Silicon oil & 920 & 5.09 & Element 14 PMDS & Obermeier \\
\hline Paraffin oil & 760 & 1.46 & Pionier 1137 & Hansen \& Rosenthal \\
\hline
\end{tabular}

Section 3.2. To verify these measurements, the separation efficiency was also determined volumetrically. The first dispersion tested consisted of water and silicon oil, the other system was a dispersion of water and paraffin oil. Table 3 shows the physical properties of the utilized oils for the disperse phases as well as their types and suppliers. For the aqueous phases tap water was used. All experiments were carried out at room temperature.

This investigation was initially focused on experiments with small amounts of dispersed phase to study only sedimentation of droplet swarms with no major impact by coalescence (which would be present at high volume fraction).

\subsection{Determination of an Adequate Probe Configuration for One Target Operating Point}

As for the fermentation broth system in Section 2, the experiments in the plate droplet separator were carried out using a flow gap at the point of measurement. The investigated droplet sizes are larger than those in the fermentation broth experiments, which is why the SOPAT $S c$ probe, which features a larger FOV, is employed. In general - depending on the fineness of the dispersion - the flow gaps are also larger in these experiments than in the fermentation broth. In Figure 11, the illumination possibilities by attaching a reflection adapter are illustrated.

With no reflection adapter being attached, see Figure 11a, only the reflected light at the interface of the particles is sent back to the optical lens system. This method only enhances each particle interface in the close vicinity of the probe tip. By applying a reflection adapter, see Figure 11b, the light that passed through the measurement volume is directed backwards to illuminate the scene from the other side. This transflection method results in photographs with higher contrast and accentuates the smaller droplets which are usually projected onto the camera sensor with lower intensity. In contrast to the transmission method, described in Section 2.2, see Fig. 5a, the transflection method does not result in brightfield photography but is characterised by a dark background.

As indicated in earlier studies, working without a reflection adapter could result in failure to identify very small droplets, (Maaß et al., 2015). Without knowledge of the measured volume's size, a reliable statement about the

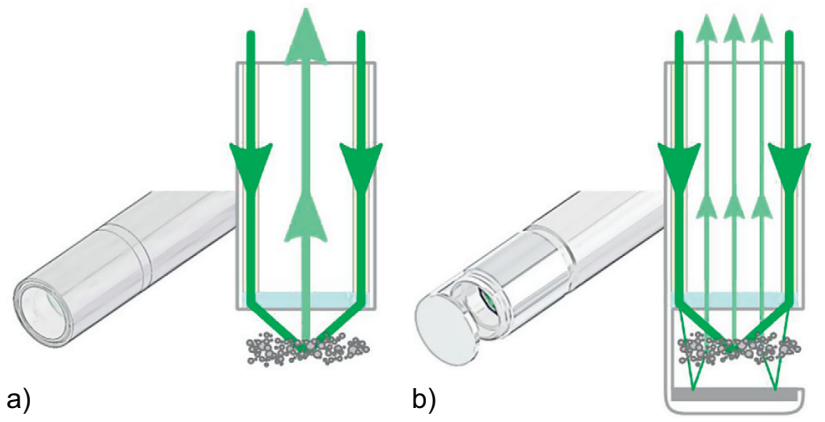

Figure 11

Illumination methods: a) reflection and b) direct transflection by use of a reflection adapter.

DSD is difficult. With higher diffuseness of the light in the photographed volume, the intensity of the projections of the particle interfaces is diminished. With a lowered intensity (almost in the magnitude of the background noise) the software is set via threshold parameters not to analyse the faint objects in order to avoid erroneous detections. Consequently, an investigation of this influence on the measured DSD was undertaken in advance of those experiments investigating the separation efficiency, see Figure 12. Herein the SOPAT $S c$ probe, mentioned above, is used at the operating point of $\dot{V}=100 \mathrm{~L} \mathrm{~h}^{-1}, \varphi_{\mathrm{d}}=1 \mathrm{vol} \%$ with silicon oil as the disperse phase and water as the continuous phase for the separator configuration with plate internals. The dispersion unit for the representative operating point chosen in this section is adjusted to produce a very fine dispersion, since the effects on the resulting detections and measured DSD are more obvious. The basic calculations used to compute the DSD are the same as those described in Section 2.3.

The units in Figure 12 describe the size of the photographed droplets in the system. In order to calculate back to the originally projected object sizes on the camera sensor, given in the camera sensor related unit of length (being pixels), the conversion factor $1.96 \mu \mathrm{m} /$ pixel has to be used. The conversion from pixels to $\mu \mathrm{m}$ is dependent on the specifics of the lens system (optical magnification). In both graphs the quantity of interest of all detected droplets, being (a) volume and (b) number, is normalised to the respective amount per image $\left(\mathrm{Img}^{-1}\right)$. In Figure 12a, a limitation of 

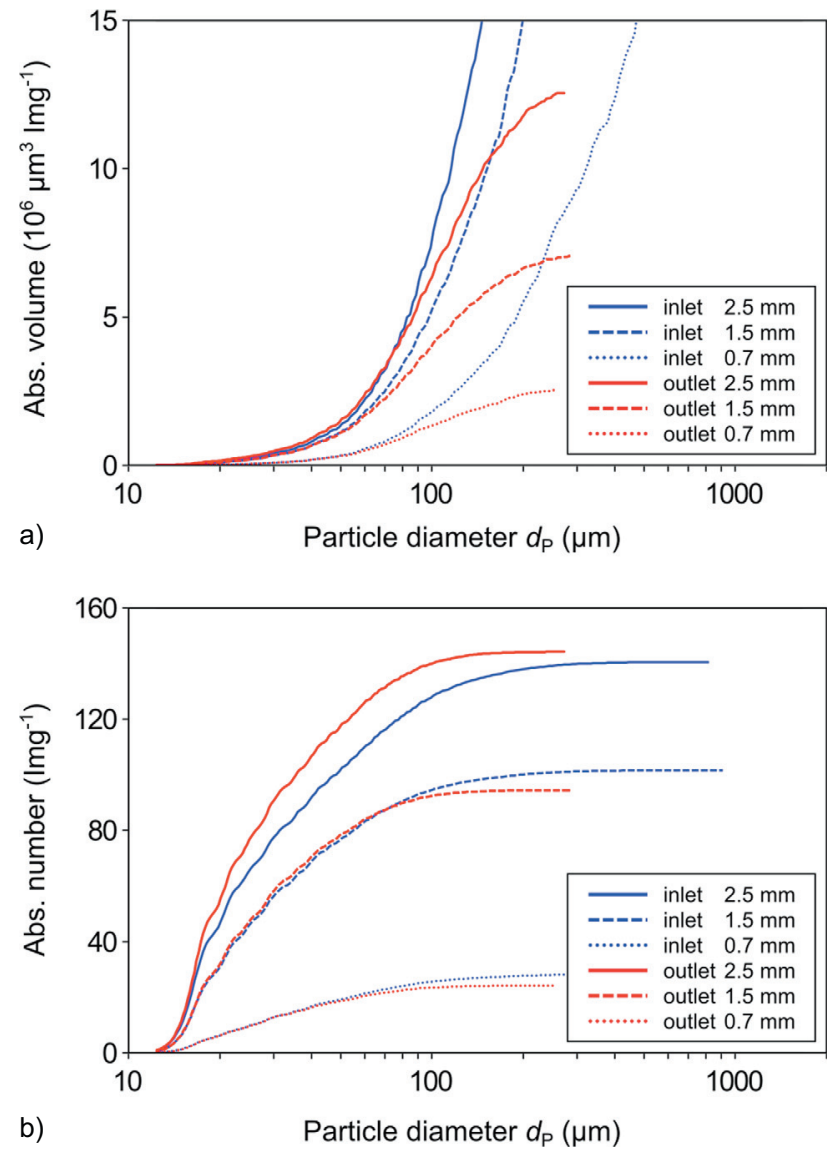

Figure 12

Measured DSD for different gap sizes at the inlet and outlet for $\dot{V}=100 \mathrm{~L} \mathrm{~h}^{-1}, \varphi_{\mathrm{d}}=1 \mathrm{vol} \%$, plotted as a) absolute volume of particles and b) absolute number of particles per image $\left(\operatorname{Img}^{-1}\right)$.

the ordinate was chosen to yield a more detailed representation of the interesting range.

As can be seen in Figure 12a, an expected distribution of droplets for the outlet related to its inlet DSD is observable. Following the red outlet curve of a certain probe configuration (i.e. reflection adapter gap size) it coincides exactly with its blue inlet curve until $c a$. $60-80 \mu \mathrm{m}$. From a certain point, which corresponds to the separation of the first small droplets, the curves diverge up to the cut-off drop size at which the red outlet curve ends. Meaning, all droplets above are entirely separated. In contrast to this familiar trend, the diagram in Figure 12b, representing the absolute particle number detected at the inlet and outlet, reveals an unexpected trend. For the trial with a flow gap of $2.5 \mathrm{~mm}$ (Fig. 12b, solid lines), the number of particles counted at the outlet is greater than the count at the inlet. According to the explanation given in the beginning of this section, this is a result of setting the gap of the reflection adapter too large, resulting in failure to identify the small particles at the inlet.

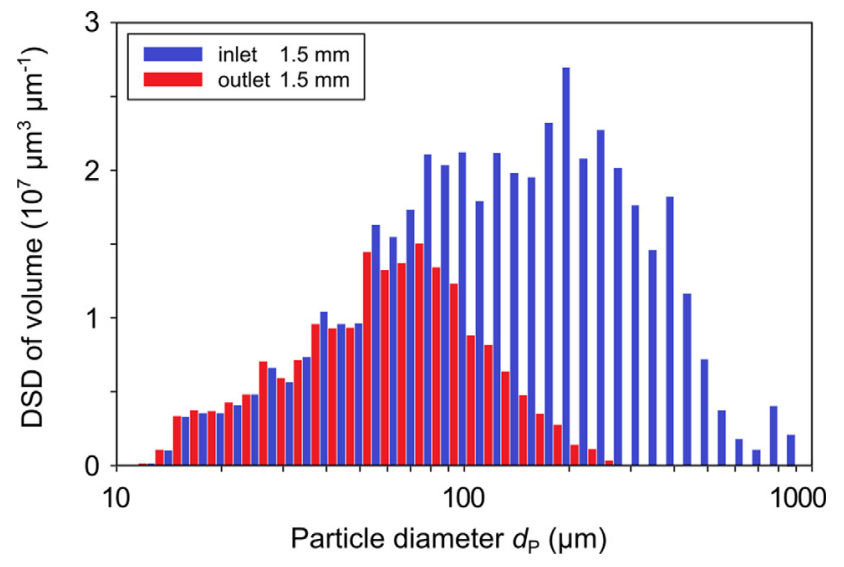

Figure 13

Measured DSD for a gap size of $1.5 \mathrm{~mm}$ at the inlet and outlet for $\dot{V}=100 \mathrm{~L} \mathrm{~h}^{-1}, \varphi_{\mathrm{d}}=1 \mathrm{vol} \%$.

Therefore, at this operating point with dispersion unit producing a very fine dispersion, the gap should be set below $1.5 \mathrm{~mm}$ when the interest lies in the absolute number rather than the volumetric relationship between inlet and outlet.

Having determined a distance of $1.5 \mathrm{~mm}$ for the flow gap, Figure 13 shows an accurate correspondence between the absolute volume density distributions of the inlet and outlet for the inseparable droplets. Hence, the fraction of droplets in the range below $d_{\mathrm{P}} \approx 60 \mu \mathrm{m}$ present at the inlet almost completely reaches the outlet of the separator. No fraction of droplets in the detectable range of the probe seems to be lost in the measured volume, neither at the inlet nor the outlet. The biggest droplets detected at this operating point (approximately $1000 \mu \mathrm{m}$, see Fig. 12b and 13) are below the maximum detectable particle size of the used probe, viz. $d_{\mathrm{P}}=1500 \mu \mathrm{m}$, see Section 3.1.

As a result of this study (preliminary to the investigation of the separation efficiency), the obtained DSD are deemed reliable in the detectable range when using a certain gap size (in the discussed case $1.5 \mathrm{~mm}$ ) dependent on the operating conditions.

\subsection{Results and Discussion}

The volumetric separation efficiency and cut-off drop size can be determined from the measurements of the inlet and outlet DSD for each experiment. In this study the cut-off drop size is the largest drop measured at the separator outlet, which hence could not be separated. Based on these values and the DSD, two examples for different operating states are compared. For each experiment, 15,000-25,000 drops were evaluated at 60-90 frames in order to minimise possible statistical inaccuracies. The basic calculations used to compute the DSD are the same as those described in Section 2.3. 


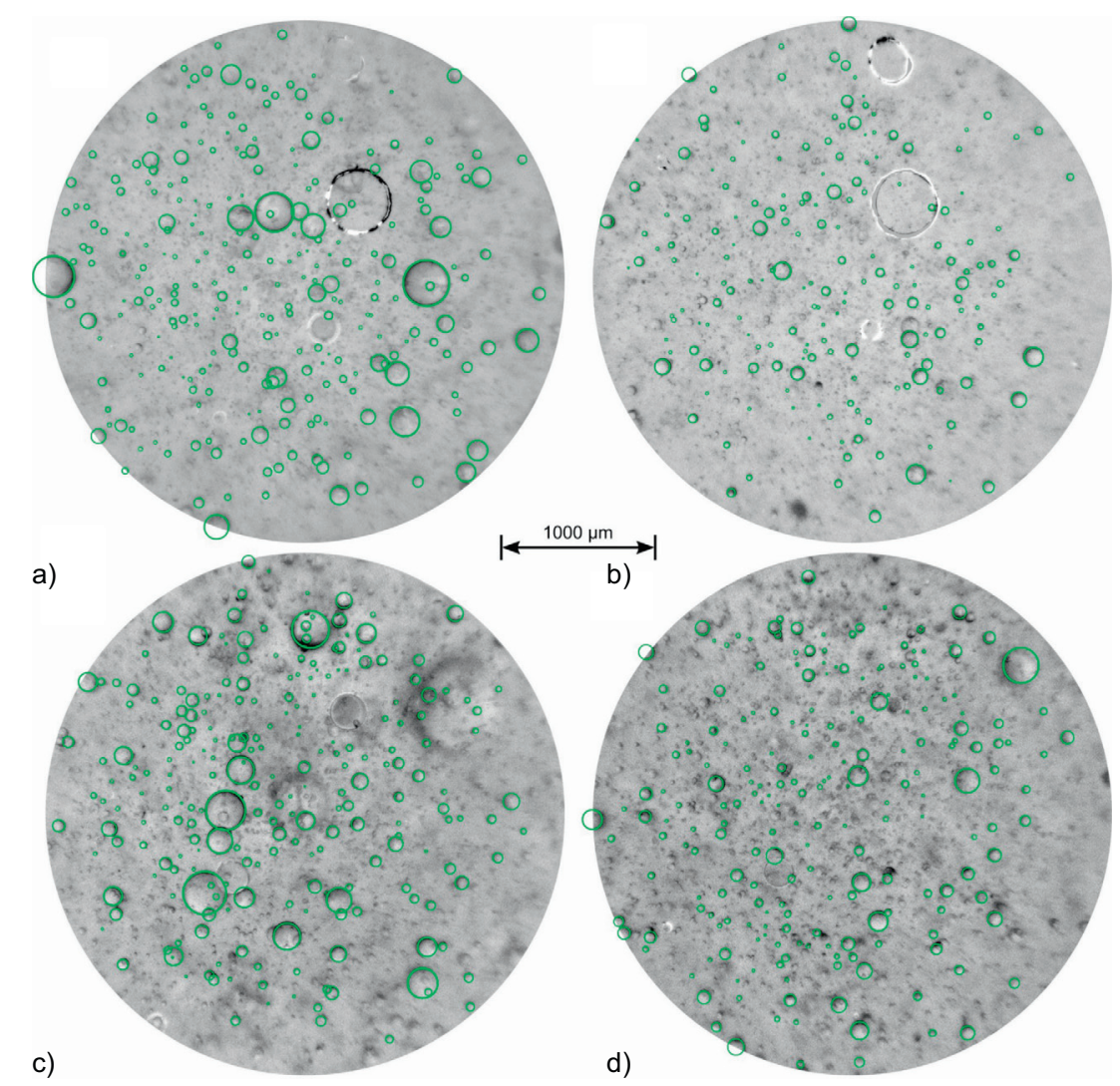

Figure 14

Representative images of the detection for $\dot{V}=200 \mathrm{~L} \mathrm{~h}^{-1}, \varphi_{\mathrm{d}}=1 \mathrm{vol} \%$, in the paraffin oil/water system at the a) inlet and b) outlet and the silicon $\mathrm{oil} /$ water system at the c) inlet and d) outlet.
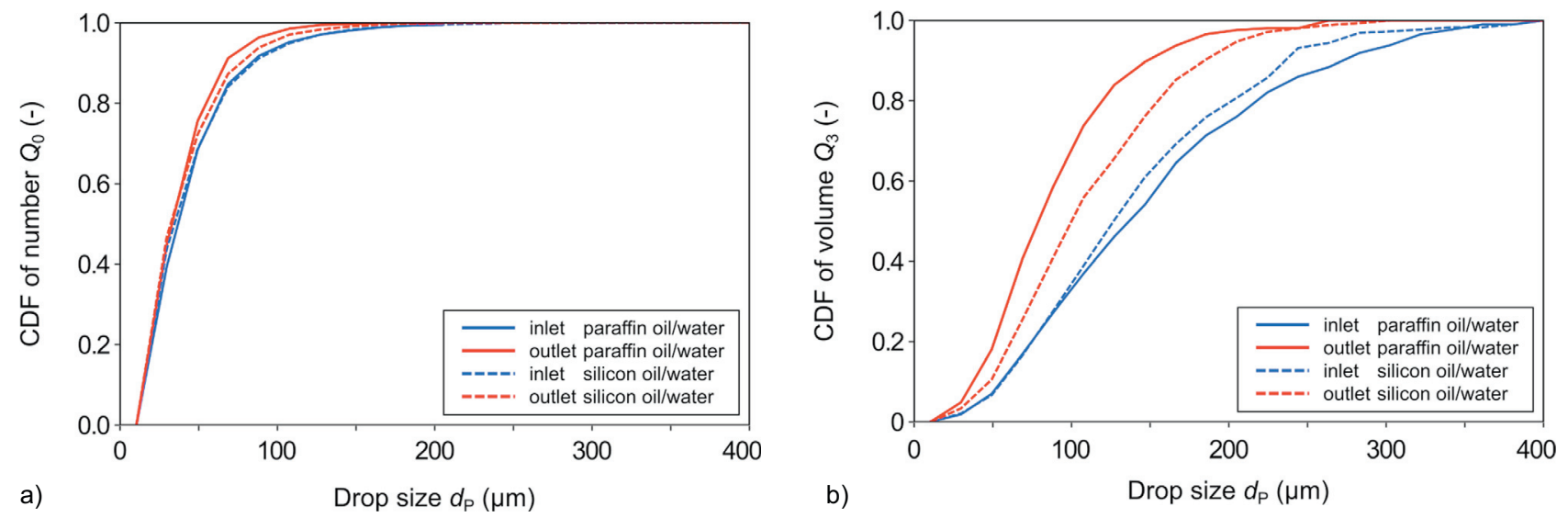

Figure 15

Comparison of the two systems for $\dot{V}=200 \mathrm{~L} \mathrm{~h}^{-1}, \varphi_{\mathrm{d}}=1 \mathrm{vol} \%$ a) cumulative DSD $Q_{0}$ of number, b) cumulative DSD $Q_{3}$ of volume.

Representative results of the detection process are given in Figure 14. In Figures 14a and $14 \mathrm{~b}$ the paraffin oil/water system is shown, and Figures $14 \mathrm{c}$ and $14 \mathrm{~d}$ show the silicon oil/water system. For both systems, the outlet droplets are clearly smaller in size and fewer in number. The very shiny objects in Figures $14 \mathrm{a}$ and $14 \mathrm{~b}$ are droplets, which stick to the lens. These are not taken into account by the software, since they do not move. 
TABLE 4

Results of the separation quality for the two investigated systems.

\begin{tabular}{c|c|c|c|c}
\hline Dispersed/main phase & $\Delta \rho\left(\mathrm{kg} \mathrm{m}^{-3}\right)$ & $\begin{array}{c}\text { Separation efficiency } \\
(\mathrm{vol} \%) \text { SOPAT }\end{array}$ & $\begin{array}{c}\text { Separation efficiency } \\
\text { (vol\%) volumetrically }\end{array}$ & $\begin{array}{c}\text { Cut-off drop size (vol\%) } \\
\text { SOPAT }\end{array}$ \\
\hline Silicon oil/water & 70 & 32 & 33 & 290 \\
\hline Paraffin oil/water & 233 & 53 & 54 & 256 \\
\hline
\end{tabular}

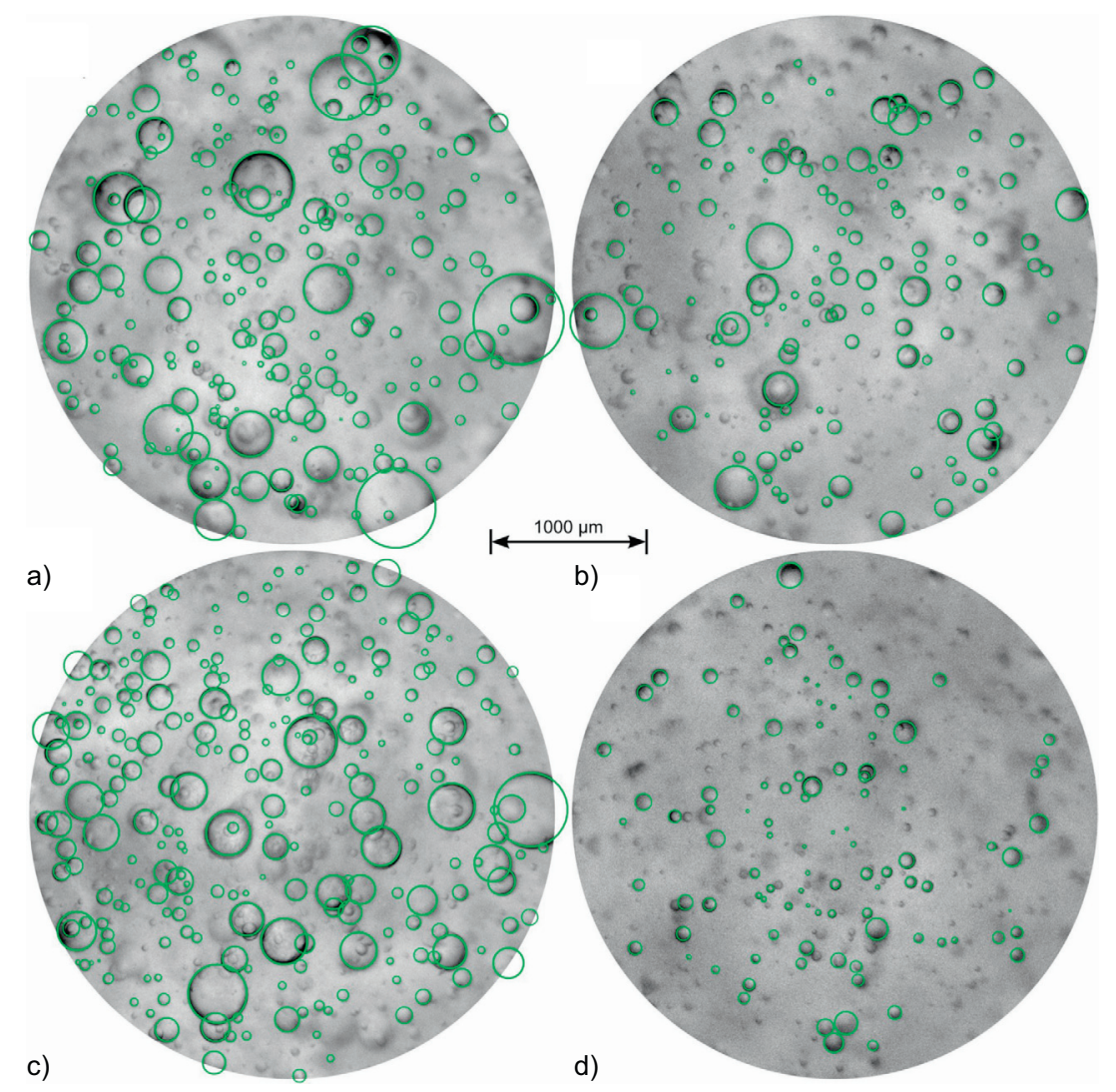

Figure 16

Representative images of the detection for the water/silicon oil system, $\dot{V}=50 \mathrm{~L} \mathrm{~h}^{-1}, \varphi_{\mathrm{d}}=5 \mathrm{vol} \%$ without plate internals at the a) inlet and b) outlet and with plate internals at the c) inlet and d) outlet.

Figure 15 shows the influence of the density difference on the separation behaviour in the gravity separator. For this purpose the DSD of the two systems, paraffin oil/water and silicon oil/water (Fig. 14), are compared under the same plant operating conditions. The dispersion unit is adjusted to produce a rather coarse dispersion. Analogous to the procedure in Section 3.2, a flow gap of $5 \mathrm{~mm}$ was determined for this larger droplet regime and applied in the separation efficiency experiments described in this section.
The photo-optical measurements clearly indicate that a lower density difference (and thus lower droplet velocities) results in slightly larger droplets at the outlet. This result is more obvious when comparing the volume distributions $Q_{3}$. In fairly broad distributions, as in these experiments, the larger droplets have a major impact on the volumetric separation. For better observation, the distributions are therefore plotted on a linear scale. Since the DSD at the separator inlet influences the volumetric separation, it has been adjusted to be as similar as possible. 

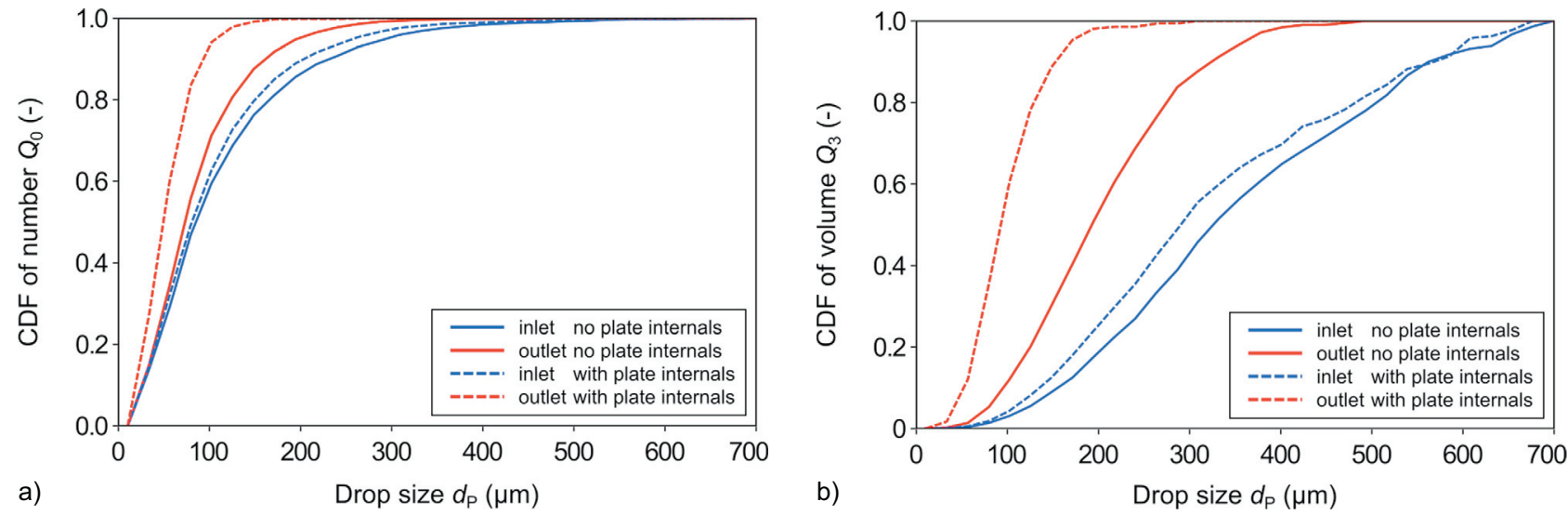

Figure 17

Comparison for the water/silicon oil system, $\dot{V}=50 \mathrm{~L} \mathrm{~h}^{-1}, \varphi_{\mathrm{d}}=5 \mathrm{vol} \%$ with and without plate internals, a) cumulative DSD $Q_{0}$ of number, b) cumulative $\operatorname{DSD} Q_{3}$ of volume.

Table 4 shows that for these experiments with a low disperse phase fraction, a very good correspondence between the volumetric degrees of separation could be achieved. As expected, the separation efficiency decreases with a reduction in the density difference, while the cut-off drop size increases.

As previously described, internals have a positive influence on the separation efficiency. They reduce the settling distance, equalize the flow distributions and provide a surface for coalescence. Consequently, results in one of the systems (water/silicon oil with water being the dispersed phase) for two configurations, with and without plate internals, are compared. The operating conditions were kept the same as before. The plates have a distance of $7 \mathrm{~mm}$ and the length of the plate package in the flow direction is $210 \mathrm{~mm}$. As shown in Section 3.2 for small droplet fractions, the measuring gap between the probe tip and the reflecting surface has to be reduced for experiments with a higher concentration of the disperse phase to minimise the likelihood of failure to identify small droplets. The adjusted gap of $5 \mathrm{~mm}$ fulfills this requirement for the coarse dispersion and $\varphi_{\mathrm{d}}=5 \mathrm{vol} \%$.

Figure 16 shows representative images of the detection for the water/silicon oil system at the operating point $\dot{V}=50 \mathrm{~L} \mathrm{~h}^{-1}, \varphi_{\mathrm{d}}=5 \mathrm{vol} \%$. When comparing the inlet distribution, see Figures 16a and 16b, with the silicon oil/water system at the operating point $\dot{V}=200 \mathrm{~L} \mathrm{~h}^{-1}, \varphi_{\mathrm{d}}=1 \mathrm{vol} \%$, see Figure 14c, a coarser distribution shifted to larger droplet diameters can be seen in the experiments with water as the disperse phase. Furthermore, the fact that the plate internals result in a higher separation efficiency is clearly observable by comparing the outlets, Figures $16 \mathrm{~b}$ and $16 \mathrm{~d}$.

Figure 17 shows the comparison of inlet and outlet DSD. Similarly for these experiments, the DSD at the inlet was adjusted to be as similar as possible. It is clearly visible,
TABLE 5

Results of the separation quality for the water/silicon oil system for two configurations, with and without plate internals.

\begin{tabular}{c|c|c|c}
\hline & $\begin{array}{c}\text { Separation } \\
\text { efficiency } \\
\text { (vol\%) SOPAT }\end{array}$ & $\begin{array}{c}\text { Separation } \\
\text { efficiency } \\
\text { (vol\%) } \\
\text { volumetrically }\end{array}$ & $\begin{array}{c}\text { Cut-off drop } \\
\text { size (vol\%) } \\
\text { SOPAT }\end{array}$ \\
\hline Without plates & 68 & 69 & 490 \\
\hline With plates & 90 & 95 & 300 \\
\hline
\end{tabular}

particularly in the volume distribution $Q_{3}$, that the size of the droplets at the separator outlet can be reduced significantly by the inclusion of plate internals. This mainly affects the volumetric separation efficiency.

Under the operating conditions above, the photo-optically obtained separation efficiencies are in accordance with those volumetrically measured, see Table 5.

\section{CONCLUSION}

The experiments carried out in the separation application clearly showed a big influence of the density difference as well as the presence of plate internals on the separation efficiency. The effect of both parameters on the change of the DSD from inlet to outlet was observed by a photo-optical method. Examining its reliability with volumetric measurements showed very good agreement.

The photo-optical measuring method shows potential for DSD measurement during microbial fermentations, since it detects a broad range of droplet sizes and allows differentiation from other disperse components such as microbial cells and bubbles. In the model mixture tested, the SMD $d_{3,2}$ ranged between 70 and $110 \mu \mathrm{m}$, while in actual fermentations for the production of biofuels expected mean droplet 
sizes are $c a .10 \mu \mathrm{m}$. Ongoing research will focus on strategies for promoting droplet coalescence and avoiding droplet stabilisation during fermentation.

It could be shown clearly that the demonstrated particle measurement system precisely determined the influence of the varied parameters on the separation efficiency. It is able to perform well even in very opaque media like fermentation broth. Additionally, it could not only detect the required DSD, but was also able to distinguish between different disperse phases, such as disturbing bubbles, yeast agglomerates and dirt particles. As the results are available inline and in real-time, a closed control loop can be established in the future.

\section{ACKNOWLEDGMENTS}

We would like to thank Susana Pedraza de la Cuesta and Caroline van Houten from Delft University of Technology for preparing the fermentation broth and for their assistance during the droplet size measurements.

\section{REFERENCES}

Abidin M.I.I.Z., Raman A.A.A., Nor M.I.M. (2013) Review on measurement techniques for drop size distribution in a stirred vessel, Ind. Eng. Chem. Res. 52, 46, 16085-16094.

Brown D.A.R., Jones P.N., Middleton J.C., Papadopoulos G., Arik E.B. (2004) Experimental methods, in: E.L. Paul, V.A. Atiemo-Obeng, S.M. Kresta (eds), Handbook of Industrial Mixing: Science and Practice, John Wiley \& Sons, Inc., Hoboken, NJ, USA, pp. 145-256.

Cuellar M.C., Zijlmans T.W., Straathof A.J.J., Heijnen J.J., van der Wielen L.A.M. (2009) Model-based evaluation of cell retention by crossflow ultrafiltration during fed-batch fermentations with Escherichia coli, Biochem. Eng. J. 44, 2-3, 280-288.

Cuellar M.C., van der Wielen L.A.M. (2015) Recent advances in the microbial production and recovery of apolar molecules, Curr. Opin. Biotech. 33, 39-45.

Furtado G.F., Picone C.S.F., Cuellar M.C., Cunha R.L. (2015) Breaking oil-in-water emulsions stabilized by yeast, Colloids Surf. $B$ 128, 568-576.

Glonke S., Sadowski G., Brandenbusch C. (2016) Applied catastrophic phase inversion: a continuous non-centrifugal phase separation step in biphasic whole-cell biocatalysis, J. Ind. Microbiol. Biotechnol. 43, 1527-1535.

Gopalan R., Jacobs D. (2010) Comparing and combining lighting insensitive approaches for face recognition, Comput. Vis. Image Underst. 114, 135-145.
Heeres A.S., Picone C.S.F., van der Wielen L.A.M., Cunha R.L., Cuellar M.C. (2014) Microbial advanced biofuels production: overcoming emulsification challenges for large-scale operation, Trends Biotechnol. 32, 4, 221-229.

Heeres A.S., Schroën K., Heijnen J.J., van der Wielen L.A.M., Cuellar M.C. (2015) Fermentation broth components influence droplet coalescence and hinder advanced biofuel recovery during fermentation, Biotechnol. J. 10, 8, 1206-1215.

Heeres A.S., Heijnen J.J., van der Wielen L.A.M., Cuellar M.C. (2016) Gas bubble induced oil recovery from emulsions stabilised by yeast components, Chem. Eng. Sci. 145, 31-44.

Legg P.A., Rosin P.L., Marshall D., Morgan J.E. (2013) Improving accuracy and efficiency of mutual information for multi-modal retinal image registration using adaptive probability density estimation, Comput. Med. Imaging Graph. 37, 7-8, 597-606.

Lewis J.P. (1995) Fast template matching, in: Vision Interface 95, Canadian Image Processing and Pattern Recognition Society, Quebec City, Canada, pp. 120-123.

Maaß S., Reinecke L., Panckow R.P., Franken H. (2015) Optimierte Feinsttropfenabscheidung mittels Echtzeittropfengrößenanalyse, Chem. Ing. Tech. 87, 8, 1078.

Maaß S., Rojahn J., Hänsch R., Kraume M. (2012) Automated drop detection using image analysis for online particle size monitoring in multiphase systems, Comput. Chem. Eng. 45, 27-37.

Mungma N., Chuttrakul P., Pfennig A. (2014) Liquid-liquid phase separation in batch settling with inclined plate, Jurnal Teknologi (Sciences \& Engineering) 67, 4, 55-58.

Panckow R.P., Comandè G., Maßß S., Kraume M. (2015) Determination of particle size distributions in multiphase systems containing nonspherical fluid particles, Chem. Eng. Technol. 38, 11, 2011-2016.

Ritter J., Kraume M. (1999) Local drop size distributions in agitated liquid-liquid dispersions of various dispersed phase fractions, in: F. Gilles F. (ed.), Proc. 2nd European Congress of Chemical Engineering, Montpellier, pp. 153-160.

Ritter J., Kraume M. (2000) On-line measurement technique for drop size distributions in liquid/liquid systems at high dispersed phase fractions, Chem. Eng. Technol. 23, 7, 579-581.

Rojas-Domínguez A., Holguín-Salas A., Galindo E., Corkidi G. (2015) Gradient-direction-pattern transform for automated measurement of oil drops in images of multiphase dispersions, Chem. Eng. Technol. 38, 2, 327-335.

Schlieper L., Chatterjee M., Henschke M., Pfennig A. (2004) Liquid-liquid phase separation in gravity settler with inclined plates, AIChE J. 50, 4, 802-811.

Schlüter M. (2011) Local Measurement Techniques for Multiphase Flows, Chem. Ing. Tech. 83, 7, 992-1004.

Sturges H.A. (1926) The choice of a class interval, J. Am. Stat. Assoc. 153, 21, 65-66.

Manuscript submitted in October 2016

Manuscript accepted in March 2017

Published online in May 2017

Cite this article as: R.P. Panckow, L. Reinecke, M.C. Cuellar and S. Maaß (2017). Photo-Optical In-Situ Measurement of Drop Size Distributions: Applications in Research and Industry, Oil Gas Sci. Technol 72, 14. 